\title{
Generalized conditions for starlikeness and convexity of certain analytic functions
}

Neslihan Uyanik ${ }^{1}$ and Shigeyoshi Owa ${ }^{2^{*}}$

\author{
* Correspondence: owa@math. \\ kindai.ac.jp \\ ${ }^{2}$ Department of Mathematics, Kinki \\ University, Higashi-Osaka, Osaka \\ 577-8502, Japan \\ Full list of author information is \\ available at the end of the article
}

\begin{abstract}
For analytic functions $f(z)$ in the open unit disk $\mathbb{U}$ with $f(0)=0$ and $f^{\prime}(0)=1$, Nunokawa et al. (Turk J Math 34, 333-337, 2010)have shown some conditions for starlikeness and convexity of $f(z)$. The object of the present paper is to derive some generalized conditions for starlikeness and convexity of functions $f(z)$ with examples. 2010 Mathematics Subject Classification: Primary 30C45.
\end{abstract}

Keywords: Analytic function, starlike function, convex function

\section{Introduction}

Let $\mathcal{A}$ denote the class of functions $f(z)$ of the form

$$
f(z)=z+\sum_{n=2}^{\infty} a_{n} z^{n}
$$

which are analytic in the open unit disk $\mathbb{U}=\{z \in \mathbb{C}:|z|<1\}$. Let $\mathcal{S}$ be the subclass of $\mathcal{A}$ consisting of functions $f(z)$ which are univalent in $\mathbb{U}$. A function $f(z) \in \mathcal{S}$ is said to be starlike with respect to the origin in $\mathbb{U}$ if $f(\mathbb{U})$ is the starlike domain. We denote by $\mathcal{S}^{*}$ the class of all starlike functions $f(z)$ with respect to the origin in $\mathbb{U}$. Furthermore, if a function $f(z) \in \mathcal{S}$ satisfies $z f^{\prime}(z) \in \mathcal{S}^{*}$, then $f(z)$ is said to be convex in $\mathbb{U}$. We also denote by $\mathcal{K}$ the class of all convex functions in $\mathbb{U}$. Note that $\mathcal{K} \subset \mathcal{S}^{*} \subset \mathcal{S} \subset \mathcal{A}$.

To discuss the univalency of $f(z) \in \mathcal{A}$, Nunokawa [1] has given

Lemma 1.1 If $f(z) \in$ Asatisfies $\left|f^{\prime \prime}(z)\right|<1(z \in \mathbb{U})$, then $f(z) \in \mathcal{S}$. Also, Mocanu [2] has shown that

Lemma 1.2 If $f(z) \in$ Asatisfies

$$
\left|f^{\prime}(z)-1\right|<\frac{2}{\sqrt{5}} \quad(z \in \mathbb{U}),
$$

then $f(z) \in \mathcal{S}^{*}$.

In view of Lemmas 1.1 and 1.2, Nunokawa et al. [3] have proved the following results.

Lemma 1.3 If $f(z) \in$ Asatisfies

$$
\left|f^{\prime \prime}(z)\right| \leqq \frac{2}{\sqrt{5}}=0.8944 \ldots \quad(z \in \mathbb{U})
$$

Then $f(z) \in \mathcal{S}^{*}$. 
Lemma 1.4 If $f(z) \in$ Asatisfies

$$
\left|f^{\prime \prime}(z)\right| \leqq \frac{1}{\sqrt{5}}=0.4472 \ldots \quad \mid(z \in \mathbb{U}),
$$

then $f(z) \in \mathcal{K}$.

The object of the present paper is to consider some generalized conditions for functions $f(z)$ to be in the classes $\mathcal{S}^{*}$ or $\mathcal{K}$.

\section{Generalized conditions for starlikeness}

We begin with the statement and the proof of generalized conditions for starlikeness.

Theorem 2.1 If $f(z) \in$ Asatisfies

$$
\left|f^{(j)}(z)\right| \leqq \frac{2}{\sqrt{5}}-M \quad(z \in \mathbb{U}),
$$

for some $j(j=2,3,4, \ldots)$, then $f(z) \in \mathcal{S}^{*}$, where

$$
M= \begin{cases}0 & (j=2) \\ \sum_{n=2}^{j-1}\left|f^{(n)}(0)\right| & (j \geqq 3) .\end{cases}
$$

Proof For $j=2$, the inequality (2.1) becomes (1.2) of Lemma 1.2. Thus, the theorem is hold true for $j=2$. We need to prove the inequality for $j \geqq 3$. Note that

$$
f^{\prime \prime}(z)=\int_{0}^{z} f^{\prime \prime \prime}(t) d t+f^{\prime \prime}(0) .
$$

We suppose that $\left|f^{\prime \prime \prime}(z)\right| \leqq N_{3}(z \in \mathbb{U})$. Then, (2.3) gives us that

$$
\begin{aligned}
\left|f^{\prime \prime}(z)\right| & \leqq \int_{0}^{|z|}\left|f^{\prime \prime \prime}\left(\rho e^{i \theta}\right) \mathrm{d} \rho\right|+\left|f^{\prime \prime}(0)\right| \\
& \leqq N_{3}|z|+\left|f^{\prime \prime}(0)\right| \\
& <N_{3}+\left|f^{\prime \prime}(0)\right| .
\end{aligned}
$$

Therefore, if $f(z)$ satisfies

$$
\left|f^{\prime \prime}(z)\right|<N_{3}+\left|f^{\prime \prime}(0)\right| \leqq \frac{2}{\sqrt{5}} \quad(z \in \mathbb{U}),
$$

then $f(z) \in \mathcal{S}^{*}$ by Lemma 1.3. This means that if $f(z)$ satisfies

$$
\left|f^{\prime \prime \prime}(z)\right| \leqq N_{3} \leqq \frac{2}{\sqrt{5}}-\left|f^{\prime \prime}(0)\right| \quad(z \in \mathbb{U}),
$$

then $f(z) \in \mathcal{S}^{*}$. Thus, the theorem is holds true for $j=3$.

Next, we suppose that the theorem is true for $j=2,3,4, \ldots,(k-1)$. Then, letting $\left|f^{(k)}(z)\right| \leqq N_{k} \quad(z \in \mathbb{U})$, we have that 


$$
\begin{aligned}
\left|f^{(k-1)}(z)\right| & =\left|\int_{0}^{z} f^{(k)}(t) \mathrm{d} t+f^{(k-1)}(0)\right| \\
& \leqq N_{k}|z|+\left|f^{(k-1)}(0)\right| \\
& <N_{k}+\left|f^{(k-1)}(0)\right| .
\end{aligned}
$$

Thus, if $f(z)$ satisfies

$$
\begin{aligned}
\left|f^{(k-1)}(z)\right| & <N_{k}+\left|f^{(k-1)}(0)\right| \\
& \leqq \frac{2}{\sqrt{5}}-\sum_{n=2}^{k-2}\left|f^{(n)}(0)\right|
\end{aligned}
$$

then $f(z) \in \mathcal{S}^{*}$. This is equivalent to

$$
\left|f^{(k)}(z)\right| \leqq N_{k} \leqq \frac{2}{\sqrt{5}}-\sum_{n=2}^{k-1}\left|f^{(n)}(0)\right| .
$$

Therefore, the theorem holds true for $j=k$. Thus, applying the mathematical induction, we complete the proof of the theorem.

Example 2.1 Let us consider a function

$$
f(z)=z+a_{2} z^{2}+a_{3} z^{3}+a_{4} z^{4}
$$

Since

$$
\left|f^{\prime \prime \prime}(z)\right|=24\left|a_{4}\right|,
$$

if $f(z)$ satisfies

$$
24\left|a_{4}\right| \leqq \frac{2}{\sqrt{5}}-2\left|a_{2}\right|-6\left|a_{3}\right|,
$$

then $f(z) \in \mathcal{S}^{*}$. This is equivalent to

$$
\sqrt{5}\left|a_{2}\right|+3 \sqrt{5}\left|a_{3}\right|+12 \sqrt{5}\left|a_{4}\right| \leqq 1 .
$$

Therefore, we put

$$
a_{2}=\frac{e^{i \theta_{1}}}{2 \sqrt{5}}, \quad a_{3}=\frac{e^{i \theta_{2}}}{9 \sqrt{5}}, \quad a_{4}=\frac{e^{i \theta_{3}}}{72 \sqrt{5}} .
$$

Consequently, we see that the function

$$
f(z)=z+\frac{e^{i \theta_{1}}}{2 \sqrt{5}} z^{2}+\frac{e^{i \theta_{2}}}{9 \sqrt{5}} z^{3}+\frac{e^{i \theta_{3}}}{72 \sqrt{5}} z^{4}
$$

is in the class $\mathcal{S}^{*}$.

\section{Generalized conditions for convexity}

For the convexity of $f(z)$, we derive

Theorem 3.1 If $f(z) \in$ Asatisfies

$$
\left|f^{(j)}(z)\right| \leqq \frac{1}{j !}\left(\frac{4}{\sqrt{5}}-P\right) \quad(z \in \mathbb{U}) .
$$


for some $j(j=3,4,5, \ldots)$, then $f(z) \in \mathcal{K}$, where

$$
P=\sum_{n=2}^{j-1} n \cdot n !\left|f^{(n)}(0)\right|
$$

Proof We have to prove for $j \geqq 3$. Note that

$$
\left(z f^{\prime}(z)\right)^{\prime \prime}=2 f^{\prime \prime}(z)+z f^{\prime \prime \prime}(z)=2\left(\int_{0}^{z} f^{\prime \prime \prime}(t) \mathrm{d} t+f^{\prime \prime}(0)\right)+z f^{\prime \prime \prime}(z) .
$$

If $\left|f^{\prime \prime \prime}(z)\right| \leqq N_{3} \quad(z \in \mathbb{U})$, then we have that

$$
\begin{aligned}
\left|\left(z f^{\prime}(z)\right)^{\prime \prime}\right| & \leqq 2\left|\int_{0}^{z} f^{\prime \prime \prime}(t) \mathrm{d} t+f^{\prime \prime}(0)\right|+\left|z f^{\prime \prime \prime}(z)\right| \\
& \leqq 2 \int_{0}^{|z|}\left|f^{\prime \prime \prime}\left(\rho e^{i \theta}\right) \mathrm{d} \rho\right|+2\left|f^{\prime \prime}(0)\right|+N_{3}|z| \\
& \leqq 3 N_{3}|z|+2\left|f^{\prime \prime}(0)\right| \\
& <3 N_{3}+2\left|f^{\prime \prime}(0)\right| .
\end{aligned}
$$

We know that $f(z) \in \mathcal{K}$ if and only if $z f^{\prime}(z) \in \mathcal{S}^{*}$. Therefore, if

$$
3 N_{3}+2\left|f^{\prime \prime}(0)\right| \leqq \frac{2}{\sqrt{5}}
$$

then $z f^{\prime}(z) \in \mathcal{S}^{*}$ by means of Lemma 1.3. Thus, if

$$
\left|f^{\prime \prime \prime}(z)\right| \leqq N_{3} \leqq \frac{2}{3}\left(\frac{1}{\sqrt{5}}-\left|f^{\prime \prime}(0)\right|\right) \quad(z \in \mathbb{U})
$$

then $f(z) \in \mathcal{K}$. This shows that the theorem is true for $j=3$.

Next, we assume that theorem is true for $j=3,4,5, \ldots,(k-1)$. Then, letting $\left|f^{(k)}(z)\right| \leqq N_{k}(z \in \mathbb{U})$, we obtain that

$$
\begin{aligned}
\left|\left(z f^{\prime}(z)\right)^{(k-1)}\right| & =\left|(k-1) f^{(k-1)}(z)+z f^{(k)}(z)\right| \\
& =\left|(k-1)\left(\int_{0}^{z} f^{(k)}(t) \mathrm{d} t+f^{(k-1)}(0)\right)+z f^{(k)}(z)\right| \\
& \leqq(k-1)\left(\int_{0}^{|z|}\left|f^{(k)}\left(\rho e^{i \theta}\right) \mathrm{d} \rho\right|+\left|f^{(k-1)}(0)\right|\right)+|z|\left|f^{(k)}(z)\right| .
\end{aligned}
$$

Now, we consider $\left|f^{(k)}(z)\right| \leqq N_{k}(z \in \mathbb{U})$, Then, (3.7) implies that

$$
\begin{aligned}
\left|\left(z f^{\prime}(z)\right)^{(k-1)}\right| & \leqq k N_{k}|z|+(k-1)\left|f^{(k-1)}(0)\right| \\
& <k N_{k}+(k-1)\left|f^{(k-1)}(0)\right| .
\end{aligned}
$$


Since, if

$$
\left|\left(z f^{\prime}(z)\right)^{(k-1)}\right| \leqq \frac{1}{(k-1) !}\left(\frac{4}{\sqrt{5}}-\sum_{n=2}^{k-2} n \cdot n !\left|f^{(n)}(0)\right|\right),
$$

then $f(z) \in \mathcal{K}$ (or $z f^{\prime}(z) \in \mathcal{S}^{*}$ ), if $f(z)$ satisfies that

$$
k N_{k}+(k-1)\left|f^{(k-1)}(0)\right| \leqq \frac{1}{(k-1) !}\left(\frac{4}{\sqrt{5}}-\sum_{n=2}^{k-2} n \cdot n !\left|f^{(n)}(0)\right|\right),
$$

that is, that

$$
N_{k} \leqq \frac{1}{k !}\left(\frac{4}{\sqrt{5}}-\sum_{n=2}^{k-1} n \cdot n !\left|f^{(n)}(0)\right|\right),
$$

then $f(z) \in \mathcal{K}$. Thus, the result is true for $j=k$. Using the mathematical induction, we complete the proof the theorem.

Example 3.1 We consider the function

$$
f(z)=z+a_{2} z^{2}+a_{3} z^{3}+a_{4} z^{4} .
$$

Then, if $f(z)$ satisfies

$$
24\left|a_{4}\right| \leqq \frac{1}{24}\left(\frac{4}{\sqrt{5}}-8\left|a_{2}\right|-108\left|a_{3}\right|\right),
$$

then $f(z) \in \mathcal{K}$. Since

$$
2 \sqrt{5}\left|a_{2}\right|+27 \sqrt{5}\left|a_{3}\right|+144 \sqrt{5}\left|a_{4}\right| \leqq 1
$$

we consider

$$
a_{2}=\frac{\mathrm{e}^{i \theta_{1}}}{4 \sqrt{5}}, \quad a_{3}=\frac{\mathrm{e}^{i \theta_{2}}}{81 \sqrt{5}}, \quad a_{4}=\frac{\mathrm{e}^{i \theta_{3}}}{864 \sqrt{5}} .
$$

With this conditions, the function

$$
f(z)=z+\frac{\mathrm{e}^{i \theta_{1}}}{4 \sqrt{5}} z^{2}+\frac{\mathrm{e}^{i \theta_{2}}}{81 \sqrt{5}} z^{3}+\frac{\mathrm{e}^{i \theta_{3}}}{864 \sqrt{5}} z^{4}
$$

belongs to the class $\mathcal{K}$.

If we use the same technique as in the proof of Theorem 2.1 applying Lemma 1.4, then we have

Theorem 3.2 If $f(z) \in$ Asatisfies

$$
\left|f^{(j)}(z)\right| \leqq \frac{1}{\sqrt{5}}-M \quad(z \in \mathbb{U})
$$

for some $j(j=2,3,4, \ldots)$, then $f(z) \in \mathcal{K}$, where $M$ is given by (2.2). 


\section{Author details}

'Department of Mathematics, Kazim Karabekir Faculty of Education, Atatürk University, 25240 Erzurum, Turkey

${ }^{2}$ Department of Mathematics, Kinki University, Higashi-Osaka, Osaka 577-8502, Japan

Received: 4 June 2011 Accepted: 17 October 2011 Published: 17 October 2011

\section{References}

1. Nunokawa, M: On the order of strongly starlikeness of strongly convex functions. Proc Jpn Acad. 68, $234-237$ (1993)

2. Mocanu, PT: Some starlikeness conditions for analytic function. Rev Roum Math Pures Appl. 33, 117-124 (1988)

3. Nunokawa, M, Owa, S, Polatoglu, Y, Caglar, M, Duman, EY: Some sufficient conditions for starlikeness and convexity. Turk J Math. 34, 333-337 (2010)

doi:10.1186/1029-242X-2011-87

Cite this article as: Uyanik and Owa: Generalized conditions for starlikeness and convexity of certain analytic functions. Journal of Inequalities and Applications 2011 2011:87.

\section{Submit your manuscript to a SpringerOpen ${ }^{\circ}$} journal and benefit from:

- Convenient online submission

- Rigorous peer review

- Immediate publication on acceptance

- Open access: articles freely available online

- High visibility within the field

- Retaining the copyright to your article

Submit your next manuscript at $\boldsymbol{s p r i n g e r o p e n . c o m ~}$ 